\title{
Insulin receptors in the CA1 field of hippocampus and selected blood parameters in diabetic rats fed with bilberry fruit
}

\author{
Małgorzata Matysek ${ }^{1, A-F}{ }^{\oplus}$, Kamila Borowiec ${ }^{2, A-F} \oplus$, Dominik Szwajgier ${ }^{2, A-B, E-F} \oplus$, \\ Radosław Szalak ${ }^{1, B-C, F \oplus}$, Marcin Bartłomiej Arciszewski ${ }^{1, D-F} \oplus$ \\ ${ }^{1}$ Faculty of Veterinary Medicine, Department of Animal Anatomy and Histology, University of Life Sciences, Lublin, \\ Poland \\ ${ }^{2}$ Faculty of Food Science and Biotechnology, Department of Biotechnology, Microbiology and Human Nutrition, \\ University of Life Sciences, Lublin, Poland \\ A - Research concept and design, B - Collection and/or assembly of data, C - Data analysis and interpretation, \\ $D$ - Writing the article, E - Critical revision of the article, F - Final approval of article
}

Matysek M, Borowiec K, Szwajgier D, Szalak R, Arciszewski MB. Insulin receptors in the CA1 field of hippocampus and selected blood
parameters in diabetic rats fed with bilberry fruit. Ann Agric Environ Med. 2021; 28(3): 430-436. doi: 10.26444/aaem/128879

\section{Abstract}

Introduction. Bilberry fruit is believed to be a promising factor in the treatment of diabetes mellitus. Chronic hyperglycaemia affects the function of the central nervous system, which may be manifested as changes in hypothalamic insulin signalling. Materials and method. Using DPPH and ABTS assays, total phenolic content in bilberry fruit and its antioxidant activities were examined. The selected biochemical parameters of blood (glucose, fructosamine, total cholesterol, HDL-cholesterol, LDL-cholesterol and triglycerides), as well as the expression of insulin receptors, were studied in the hippocampal CA1 field of healthy and diabetic (streptozotocin-induced; $60 \mathrm{mg} \mathrm{kg}-1$ body weight) Wistar rats fed with bilberry fruit (16 g kg-1 body weight per day; 6 weeks), as well as of the corresponding control groups.

Results. Biochemical analyses revealed ambiguous results, but a significantly $(P<0.05)$ decrease in the level of $L D L-c h o l e s t e r o l$ was observed in the group of healthy rats supplemented with bilberry pulp after 6 weeks of the treatment. There was also a difference $(P<0.05)$ in the level of LDL-cholesterol in the mentioned healthy animals fed with bilberry, versus the healthy control group. An increased number of insulin receptors-immunoreactive neurons as well as nerve fibres in the CA1 field of diabetic rats fed with bilberry fruit was also found.

Conclusions. An inclusion of bilberry fruit in the daily diet during the course of diabetes can lead to plasticity of hippocampal neurons/nerve fibres, manifested by changes in insulin receptors expression. Whether or not the observed changes had protective effects (by reducing damages caused by diabetes mellitus) on the function of the central nervous system neurons needs further study.

\section{Key words}

bilberry, insulin receptors, rats, diabetes mellitus, hippocampus

\section{INTRODUCTION}

Bilberry (Vaccinium myrtillus L.) has been used for centuries in traditional medicine. The possible application of bilberry leaves as anti-diabetic agent is commonly suggested due to the presumed ability of the phenolic compounds to decrease blood glucose and blood triglyceride levels $[1,2]$. The antidiabetic activity of bilberry is was also widely known [3, $4,5]$. Bilberry fruit is a valuable source of polyphenolic compounds, i.e. anthocyanins and flavonols, including quercetin [6], which can protect against oxidative stress and minimize the risk of tissue injury caused by diabetes [7]. Antioxidant properties of the bilberry extract have also been proved in STZ-diabetic adult Swiss albino mice [8]. Bilberry fruit can be also considered a rich source of acetyl- and butyrylcholinesterase inhibitors $[9,10]$, that is, compounds which are approved worldwide for use in treatment during the mild and moderate stages of Alzheimer's disease (AD).

Address for correspondence: Kamila Borowiec, University of Life Sciences, Faculty of Food Science and Biotechnology, Department of Biotechnology, Microbiology and Human Nutrition, Skromna 8, 20-704, Lublin, Poland

E-mail: kamila.borowiec@up.lublin.pl

Received: 23.07.2020; accepted: 26.10.2020; first published: 20.11.2020
According to the results of previous studies, it is highly likely that patients who suffer from diabetes mellitus (DM) will also develop AD and it is even called type III diabetes [11, 12]. The relationship between $\mathrm{DM}$ and $\mathrm{AD}$ is being widely investigated using animal models, including a model of DM induction as a result of STZ injection $[2,4,8]$.

The effect of chronic hyperglycaemia comprises accelerated brain aging [13] and indivertible changes in the structures of the central nervous system (CNS) [14], eventually causing memory impairments. In addition, it has been found that in DM, nerve cells do not respond to insulin due to the dysfunction of insulin receptors (InRs) [15]. InRs are unevenly distributed in different brain compartments with high concentrations being identified in the hippocampus area responsible for cognitive functions [16]. Insulin is indispensable for the proper functioning of the brain by stimulating InRs located in the synaptic membrane, thus participating in the process of creating new synaptic connections [17]. As a result, at optimum concentrations of $100 \mu \mathrm{U}$ or $1 \mathrm{mU}$, insulin modulates memory processes in the healthy brain [18]. 


\section{OBJECTIVE}

The aim of the presented study was to compare the expression of InRs in the CA1 field of hippocampus in healthy and diabetic rats fed bilberry fruit-rich diets, and thus to determine whether or not antioxidants present in bilberry fruit may potentially act as neuroprotective factors. In addition, the levels of diabetic markers, such as blood glucose and fructosamine, as well as lipid profile, were examined in non-diabetic and diabetic rats fed for 6 weeks with bilberry pulp, or only standard unmodified feed to control the most usual complications in DM (hyperglycemia and abnormal lipid profile).

\section{MATERIALS AND METHOD}

Bilberry preparation. Fresh bilberry fruit harvested in forests in the Lublin region of eastern Poland was purchased at a local market in Lublin. The identity of fruit samples was authenticated by Prof. Kazimierz Głowniak at the Department of Pharmacognosy/Medicinal Plant Laboratory, at the Medical University in Lublin. Bilberries were mashed up using a Thermomix TM31 (Vorwerk, Wuppertal, Germany) for 3 min (maximum speed at ambient temperature) followed by portioning and freezing $\left(-20^{\circ} \mathrm{C}\right)$ for animal's diet and total phenolic content (TPC) assay or centrifugation $\left(4^{\circ} \mathrm{C}, 13,131 \mathrm{~g}\right.$, $30 \mathrm{~min}$ ) for analyses of antioxidant effects.

Determination of dry matter content in bilberry pulp. The dry matter content of bilberry was determined in accordance with Polish Standards PN-A-75101-03: 1990. The prepared bilberry pulp (see Bilberry preparation) was dried $\left(105 \pm 5^{\circ} \mathrm{C}\right)$ in duplicate until constant weight was obtained.

TPC assay. $5 \mathrm{~g}$ of homogenized berries were extracted with 50 $\mathrm{mL}$ of methanol at ambient temperature for $1 \mathrm{~h}$ with constant shaking. The solution was filtered and the residue repeatedly extracted with $50 \mathrm{~mL}$ of methanol for $1 \mathrm{~h}$. Finally, the extracts were blended and diluted to $500 \mathrm{~mL}$ with methanol. The TPC in berry extracts was determined using Folin-Ciocalteu reagent (Sigma-Aldrich, St. Louis, MO, USA), as reported previously [19]. The reagent was prepared by diluting a stock solution with distilled water $(1: 10, \mathrm{v} / \mathrm{v}) .1 \mathrm{~mL}$ of the sample was placed in testing cuvettes and mixed with $5 \mathrm{~mL}$ of Folin-Ciocalteu's phenol reagent and $4 \mathrm{~mL}$ of sodium carbonate $(7.5 \%)$. Absorbance was measured at $765 \mathrm{~nm}$ in a UV-Vis spectrophotometer UV-1280 (Shimadzu Europa $\mathrm{GmbH}$, Duisburg, Germany) after incubation at ambient temperature for $1 \mathrm{~h}$, TPC was determined based on the calibration curve and expressed in mg of gallic acid (SigmaAldrich) equivalents (GAE) per $100 \mathrm{~g}$ of berries (fresh weight, FW). All samples were examined in 4 replicates.

Antioxidant activity measured using 1,1-diphenyl-2picrylhydrazyl (DPPH). The method of Brand-Williams et al. [20] was used with own modifications. $0.020 \mathrm{~mL}$ of bilberry juice $\left(25 \mathrm{mg}\right.$ dry mass $\left.\mathrm{mL}^{-1}\right)$ was mixed with 0.080 $\mathrm{mL}$ of distilled de-ionized (DDI) water and $0.090 \mathrm{~mL}$ of DPPH (Sigma-Aldrich) solution in methanol (0.06 mM). Absorbance $\left(\mathrm{A}_{1}\right)$ was read at $515 \mathrm{~nm}$ over $5 \mathrm{~min}$ at $30 \mathrm{~s}$ intervals $\left(20^{\circ} \mathrm{C}\right.$, 96-well microplate reader Tecan Sunrise, Grödig, Austria). Negative blank samples (DDI water instead of bilberry juice) were also run $\left(\mathrm{A}_{0}\right)$. Blanks containing juice and DDI water (without DPPH solution; $\mathrm{A}_{2}$ ) were considered in the final calculations: $A_{0}-\left(A_{1}-A_{2}\right)$. Antiradical activity was expressed as Trolox equivalent antioxidant capacity (TEAC value) using Trolox (Sigma-Aldrich) standard solutions in DDI water $(0.006-0.623 \mathrm{mM})$. All samples were examined in 4 replicates.

Antioxidant activity measured using 2,2'-azino-bis (3-ethylbenzothiazoline-6-sulphonic acid) (ABTS). Original methods were used with own modifications [21]. ABTS (Sigma-Aldrich) solution (in DDI water, $7 \mathrm{mM}$, containing $2.45 \mathrm{mM}$ potassium persulphate) was prepared. After $24 \mathrm{~h}$ at ambient temperature, the absorbance of ABTS at $700 \mathrm{~nm}$ was adjusted to $0.70 \pm 0.02$. Next, $0.010 \mathrm{~mL}$ of bilberry juice ( $25 \mathrm{mg}$ dry mass $\mathrm{mL}^{-1}$ ) was mixed with $0.100 \mathrm{~mL}$ of DDI water and $0.090 \mathrm{~mL}$ of ABTS solution. Absorbance $\left(\mathrm{A}_{1}\right)$ was read at $700 \mathrm{~nm}$ over $5 \mathrm{~min}$ at $30 \mathrm{~s}$ intervals $\left(20^{\circ} \mathrm{C}\right.$, Tecan Sunrise). Negative blank samples (bilberry juice replaced with DDI water) were also run ( $\left.\mathrm{A}_{0}\right)$. The absorbance of blanks containing juice and DDI water (without ABTS solution; $\mathrm{A}_{2}$ ) was also used in order to calculate the activity using the equation: $A_{0}-\left(A_{1}-A_{2}\right)$. Antiradical activity was expressed as TEAC value using Trolox standard solutions in DDI water (0.006-0.623 mM). All samples were examined in 4 replicates.

Animals. Forty $(\mathrm{n}=40)$ male Wistar rats were provided by the Centre for Experimental Medicine of the Medical University of Białystok, Poland. The study was approved by the $2^{\text {nd }}$ Local Ethics Committee at the University of Life Sciences in Lublin, Poland (License Nos. 105/2010, 15/2011 and 34/2012). All efforts were made to minimize animal suffering. Animals were caged individually with free access to feed (standard rodent feed, LSM, Agropol S.J., Motycz, Poland) and water ad libitum, and maintained on a 12-h-light/12-h-dark cycle at a temperature of $23 \pm 1^{\circ} \mathrm{C}$. Prior to the main experiment, the animals were acclimatized to the laboratory environment and to the investigators who handled them.

Forty 3-month-old animals (weight 330-420 g) were split randomly into 4 groups $(\mathrm{n}=10)$. The animal model of DM was induced in 2 groups $(n=20)$ in the overnight-fasted animals by a single intraperitoneal injection of STZ (60 mg kg-1 body weight, BW; Sigma-Aldrich). A freshly-prepared solution of STZ was dissolved in sterile citric buffer $(100 \mathrm{mM}, \mathrm{pH} 4.5)$ containing $0.9 \%(\mathrm{~m} / \mathrm{v})$ sodium chloride $(\mathrm{NaCl})$. The control group received a single intraperitoneal injection of sterile citric buffer $(100 \mathrm{mM}, \mathrm{pH} 4.5)$ containing $0.9 \%(\mathrm{~m} / \mathrm{v}) \mathrm{NaCl}$. For $48 \mathrm{~h}$, the animals drank tap water with $5 \%(\mathrm{~m} / \mathrm{v})$ glucose instead of pure tap water $[22,23]$. The elevated blood glucose and plasma fructosamine levels were determined $48 \mathrm{~h}$ after hyperglycaemia had been confirmed. Only animals with glucose and fructosamine levels above $300 \mathrm{mg} 100 \mathrm{~mL}^{-1}$ and $245 \mu \mathrm{M}$, respectively, were included in this experiment. As a result, a total of 36 rats (16 diabetic rats, 20 healthy rats) completed the experiment.

The diet supplemented with bilberry pulp was continued for 6 weeks in the following groups: diabetic group (A) that received standard feed $(n=8)$, diabetic group $(B)$ that received standard feed supplemented with bilberry pulp $(\mathrm{n}=8)$, healthy group $(\mathrm{C})$ that received standard feed supplemented with bilberry pulp $(n=10)$ and the healthy group $(D)$ that received standard feed $(n=10)$. Daily intake of standard feed was $30 \mathrm{~g}$, but in groups of animals fed with bilberry pulp, $7 \mathrm{~g}$ of 
standard feed was replaced by $16 \mathrm{~g}$ of bilberry $\mathrm{kg}^{-1} \mathrm{BW}$ per day (human equivalent dose (HED) $-3 \mathrm{~g} \mathrm{~kg}^{-1} \mathrm{BW}$ ); the amount of uneaten bilberries was controlled and counted) [24]. All rats received their respective diets until euthanized (by carbon dioxide overdose) at the age of 4.5 months. Body weight and the weight of unconsumed feed were continuously controlled.

Blood analysis. Blood was collected from the caudal vein of overnight-fasted animals anaesthetized by xylazine (Biowet, Poland; intra musculum) at the beginning of the experiment. After 6 weeks, blood samples (cardiac puncture) were taken from premedicated, overnight-fasted animals before euthanasia by carbon dioxide. Glucose levels were measured (glucometer GS, test strips Accu-Chek Go, Roche Diagnostic GmbH, Mannheim, Germany) directly after the collection of blood. Serum was separated by centrifugation (2000 g, 15 min., room temperature) and stored $\left(-20^{\circ} \mathrm{C}\right)$. The concentrations of fructosamine, total cholesterol, HDLcholesterol, LDL-cholesterol and triglycerides were estimated within $36 \mathrm{~h}$ at the Veterinary Diagnostic Laboratory LABWET in Warsaw, Poland.

Tissue sampling, immunohistochemistry and antibodies. The brains from 36 male Wistar rats were dissected out immediately after slaughter and were stored in $10 \%$ buffered formalin ( $\mathrm{pH} 7$ ) for $12 \mathrm{~h}$ at $4^{\circ} \mathrm{C}$, dehydrated in ethyl alcohol, followed by embedding in paraffin blocks according to a previously described method [25]. Briefly, the paraffin blocks were cut into $5 \mu \mathrm{m}$-thick sections which were placed on silanized glass-slides (SuperFrost Plus, Thermo Fisher Scientific GmbH, Dreieich, Germany). The sections were incubated for $24 \mathrm{~h}$ at $4{ }^{\circ} \mathrm{C}$ with primary polyclonal antibody directed against insulin R/CD220 antibody (NBP2-16970 novusbio.com, Centennial, CO, USA). Next day, the slides were washed in washing buffer $(2 \times 15 \mathrm{~min})$ and covered with anti-mouse/rabbit Ig (ImPRESS ${ }^{\mathrm{TM}}$ Reagent KIT, MP-7500 Vector, Burlingame, CA, USA) for $1 \mathrm{~h}$. For the visualization of primary antisera, 3,3'-diaminobenzidine (ImmPACT ${ }^{\mathrm{TM}} \mathrm{DAB}$, SK-4105 Vector, Burlingame, CA, USA) chromogen was used. A working solution of DAB was applied to the slides and the process monitored under a light microscope. Finally, the slides were rinsed with distilled water. Counterstaining for $20 \mathrm{~min}$ with Mayer's haematoxylin was performed. After washing in distilled water, the slides were dehydrated in an ethyl alcohol series, cleared in xylene, mounted in DPX (mountant for histology, Merck KGaA, Darmstadt, Germany) and cover slipped. The slides were viewed under a light microscope (Axio Lab, Zeiss, Jena, Germany) connected to a digital camera. From each animal, approx. 25-30 sections immunostained for insulin receptors were analyzed. The distribution of InRs were studied using Cell D software (Olympus). No fewer than 100 of InRs neurons in CA1 field were viewed and counted. The specificity of antibodies used was verified using a negative control in which primary antibodies were replaced with identical concentrations of appropriate non-immune IgG.

Statistical analysis. Results were expressed as mean \pm standard deviation (SD). An inter-group variation was measured by one way analysis of variance (ANOVA) followed by post hoc Tukey's HSD test (biochemical blood parameters) or by Kruskal-Wallis test (InRs). Statistical significance was considered at $\mathrm{P}<0.05$. STATISTICA 8.0 software (StatSoft Inc., Tulsa, OK, USA) was used.

\section{RESULTS}

TPC, DPPH and ABTS assays. The dry matter content of the bilberry pulp for the animal's diet was estimated as $13.30 \pm 0.43 \%$. In addition, the nutritional value of the bilberry fruit was performed (Tab. 1). The results of the antioxidant and antiradical assays (supplementary material) confirmed previous findings that bilberry is a valuable source of polyphenols (TPC 611.45 $\pm 43.60 \mathrm{mg} \mathrm{GAE} 100 \mathrm{~g}^{-1} \mathrm{FW}$ ) and that it 'scavenged' effectively both DPPH (TEAC $0.35 \pm 0.02$ $\mathrm{mM}$ ) and ABTS radicals (TEAC $0.46 \pm 0.01 \mathrm{mM}$ ).

Table 1. Nutritional value of $100 \mathrm{~g}$ of bilberry fruit [26]

\begin{tabular}{lcc}
\hline \multirow{2}{*}{ Energy } & 51 & $\mathrm{kcal}$ \\
\cline { 2 - 3 } & 214 & $\mathrm{~kJ}$ \\
\hline Protein & 0.80 & $\mathrm{~g}$ \\
\hline Total lipid (fat) & 0.60 & $\mathrm{~g}$ \\
\hline Fibre, total dietary & 3.20 & $\mathrm{~g}$ \\
\hline Sugars, total & 12.20 & $\mathrm{~g}$ \\
\hline Sucrose & 0.40 & $\mathrm{~g}$ \\
\hline Glucose (dextrose) & 2.90 & $\mathrm{~g}$ \\
\hline Fructose & 3.20 & $\mathrm{~g}$ \\
\hline
\end{tabular}

Biochemical analysis. Control of selected biochemical parameters of blood was performed. The concentrations of the following compounds were analyzed: glucose, fructosamine, total cholesterol, LDL-cholesterol, HDL-cholesterol and triglycerides (Fig. 1). In the study, biochemical parameters were evaluated in healthy $(\mathrm{C}-\mathrm{D})$ and diabetic $(\mathrm{A}-\mathrm{B})$ rats at the beginning of the experiment, as well as after administration of bilberry pulp for 6 weeks.

At the beginning of the experiment, the expected differences between the healthy and diabetic rats were noted; namely, the higher levels of glucose $\left(644.5 \pm 169.4 \mathrm{mg} 100 \mathrm{~mL}^{-1}\right.$ vs. $\left.153.7 \pm 29.8 \mathrm{mg} 100 \mathrm{~mL}^{-1}\right)$, fructosamine $(338.0 \pm 10.1 \mu \mathrm{M}$ vs. $185.7 \pm 13.4 \mu \mathrm{M})$, cholesterol $\left(181.0 \pm 49.2 \mathrm{mg} 100 \mathrm{~mL}^{-1}\right.$ vs. $\left.71.2 \pm 11.5 \mathrm{mg} 100 \mathrm{~mL}^{-1}\right)$ and triglycerides $(505.3 \pm 111.1 \mathrm{mg}$ $100 \mathrm{~mL}^{-1}$ vs. $117.0 \pm 33.1 \mathrm{mg} 100 \mathrm{~mL}^{-1}$ ) in group A (diabetic control) than in group $\mathrm{D}$ (healthy control) were observed $(\mathrm{P}<0.05)$. Surprisingly, even the HDL-cholesterol level was significantly $(\mathrm{P}<0.05)$ elevated in group A $(46.3 \pm 7.1 \mathrm{mg}$ $\left.100 \mathrm{~mL}^{-1}\right)$, in comparison with group $\mathrm{D}\left(26.9 \pm 4,1 \mathrm{mg} \mathrm{mL}^{-1}\right)$ (Fig. 1E).

Based on the results within the groups (comparison between the beginning and end of the study), a significant difference $(\mathrm{P}<0.05)$ in glucose concentration in group $\mathrm{B}$ (Fig. 1A) was observed. On the other hand, LDL-cholesterol levels were significantly $(\mathrm{P}<0.05)$ reduced in groups $\mathrm{C}$ and $D$. Namely, the level of LDL-cholesterol in group $C$ was significantly $(\mathrm{P}<0.05)$ reduced from $27.0 \pm 4.7 \mathrm{mg} 100 \mathrm{~mL}^{-1}$ (at the beginning of the study) to $7.3 \pm 2.9 \mathrm{mg} 100 \mathrm{~mL}^{-1}$ (after 6 weeks of the treatment) during the study (Fig. 1D). The difference $(\mathrm{P}<0.05)$ in the level of $\mathrm{LDL}$-cholesterol was also observed between groups $C$ and D after 6 weeks of the study (Fig. 1D). In addition, the concentration of HDL-cholesterol significantly $(\mathrm{P}<0.05)$ increased within groups $\mathrm{A}$ and $\mathrm{B}$ (final

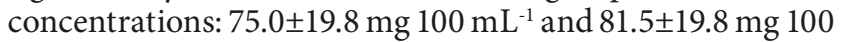
$\mathrm{mL}^{-1}$, respectively), as well as within groups $\mathrm{C}$ and $\mathrm{D}$ (final concentrations: $42.0 \pm 8.5 \mathrm{mg} 100 \mathrm{~mL}^{-1}$ and $49.5 \pm 6.4 \mathrm{mg} 100$ $\mathrm{mL}^{-1}$, respectively) after 6 weeks, regardless of whether or 

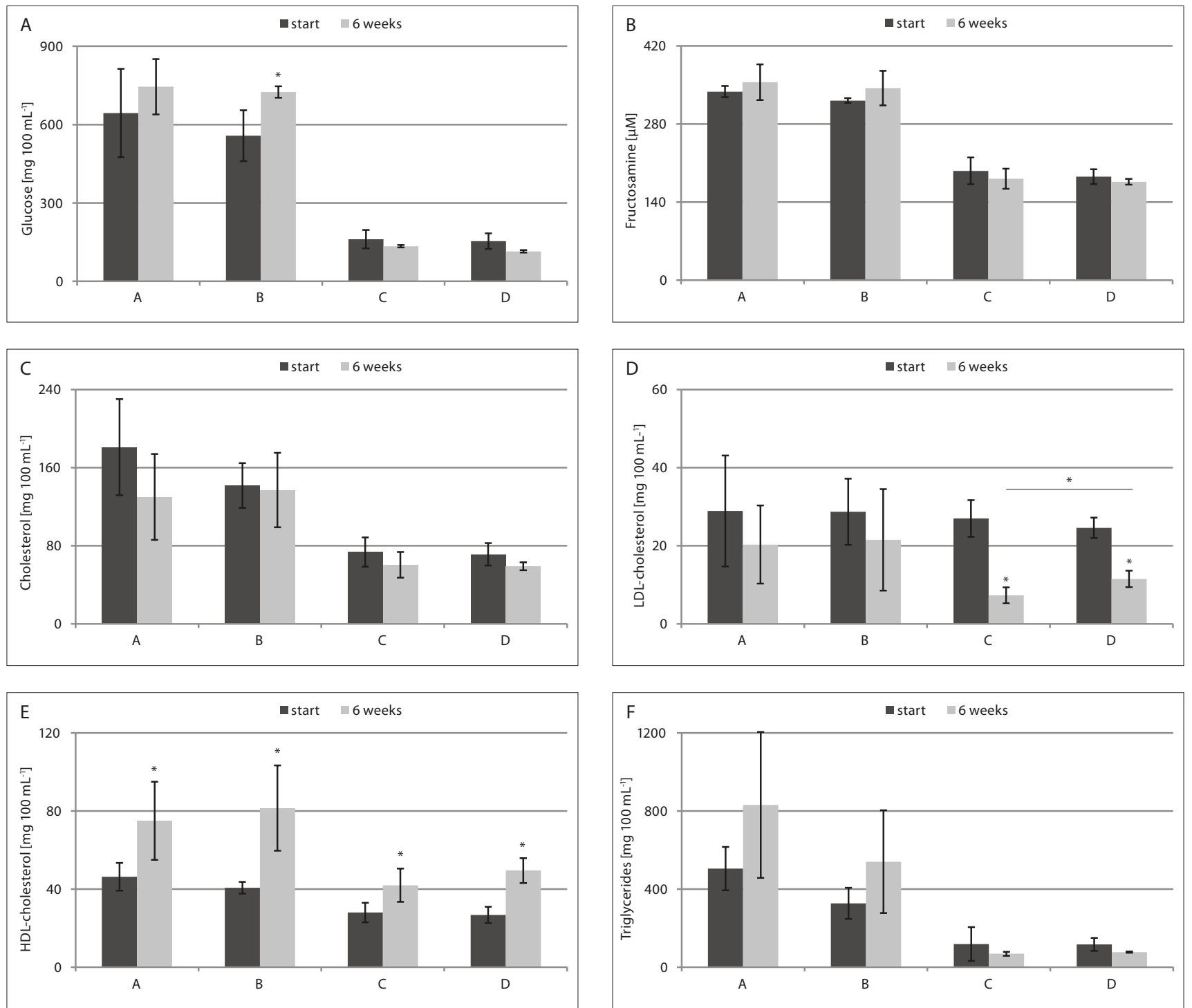

Figure 1. Effect of administration of bilberry $\left(16 \mathrm{~g} \mathrm{~kg}^{-1} \mathrm{BW}\right.$ per day) on the concentrations of glucose, fructosamine, cholesterol, LDL-cholesterol, HDL-cholesterol and triglycerides in diabetic and normal rats at the beginning and after 6 weeks of treatment.

(A) diabetic group, $n=8$; (B) diabetic group fed with bilberry pulp, $n=8 ;(C)$ healthy group fed with bilberry pulp, $n=10 ;(D)$ healthy group, $n=10$. Values are given as mean \pm SD. ${ }^{*} \mathrm{P}<0.05$

not the rats were fed with bilberry (Fig. 1E). However, no significant differences $(\mathrm{P}<0.05)$ in the levels of total cholesterol, LDL-cholesterol, HDL-cholesterol and triglycerides between group B and group A were observed after 6 weeks of the experiment (Fig. 1). Increased levels of HDL-cholesterol were observed in all studied groups after 6 weeks of the study, regardless of the inclusion of bilberry in the diet, which suggests the presence of the additional factor which could have affected the measured parameter (Fig. 1E). It is assumed that the standard rodent diet might play a crucial role in this phenomenon; namely, that the LSM diet contains 5\% fibre (supplementary material). In terms of previous findings that a high-fibre diet induced a higher plasma HDL-cholesterol level [27], it is suggested that the used standard rodent diet was the prime reason for the elevation of HDL-cholesterol levels over 6-week time of the experiment.

Also, the expected effect $(\mathrm{P}<0.05)$ of bilberry supplementation on glucose and fructosamine concentrations did not occur in the diabetic rats receiving the treatment (group B). Moreover, the glucose level was even significantly
$(\mathrm{P}<0.05)$ increased in group $\mathrm{B}$ after 6 weeks of the treatment. The most probable cause for the increased glucose level despite the administration of bilberry in the diet, is believed to be advanced pancreatic damage in the animal model of DM caused by the STZ injection.

InRs in the brain. As a result of the authors' studies, no swelling was found in InRs-immunoreactive (InRs-ir) neurons, nor changes in the size of the hippocampus after 6 weeks of the experiment. However, a significant decrease in the number of InRs-ir neurons in the hippocampal CA1 field was observed in group A, compared to the normal group D $(25.8 \pm 2.4 \%$ vs. $63.6 \pm 3.2 \%$, respectively) (Fig. 2$)$. In group $\mathrm{D}$, it was confirmed that InRs-ir neurons showed an intense $(+++)$ nuclear/cytoplasmic (nuct/cyt+) reaction. InRs-ir neurons prevailed in the pyramidal layer of the hippocampal CA1 field, as well as in the marginal layer. In contrast, in group A, the nuclear/cytoplasmic reaction was weak (+) and individual InRs-ir neurons were located only in the layer of pyramidal cells of the CA1 hippocampal field. 


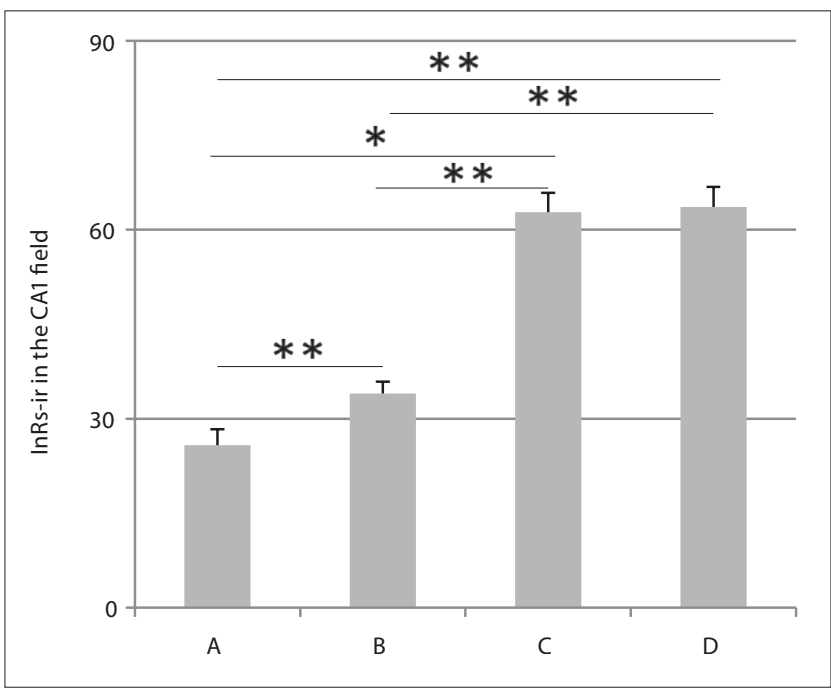

Figure 2. Effect of administration of bilberry $\left(16 \mathrm{~g} \mathrm{~kg}^{-1} \mathrm{BW}\right.$ per day) on the number of InRs-ir neurons in the CA1 field of hippocampus in diabetic and healthy rats. (A) diabetic group, $n=8$; (B) diabetic group fed with bilberry pulp, $n=8$; (C) healthy group fed with bilberry pulp, $n=10 ;(D)$ healthy group, $n=10$. Values are given as mean \pm SD. Statistically significant differences for: *ANOVA $P<0.05$; **KRUSKALWALLIS $\mathrm{P}<0.05$
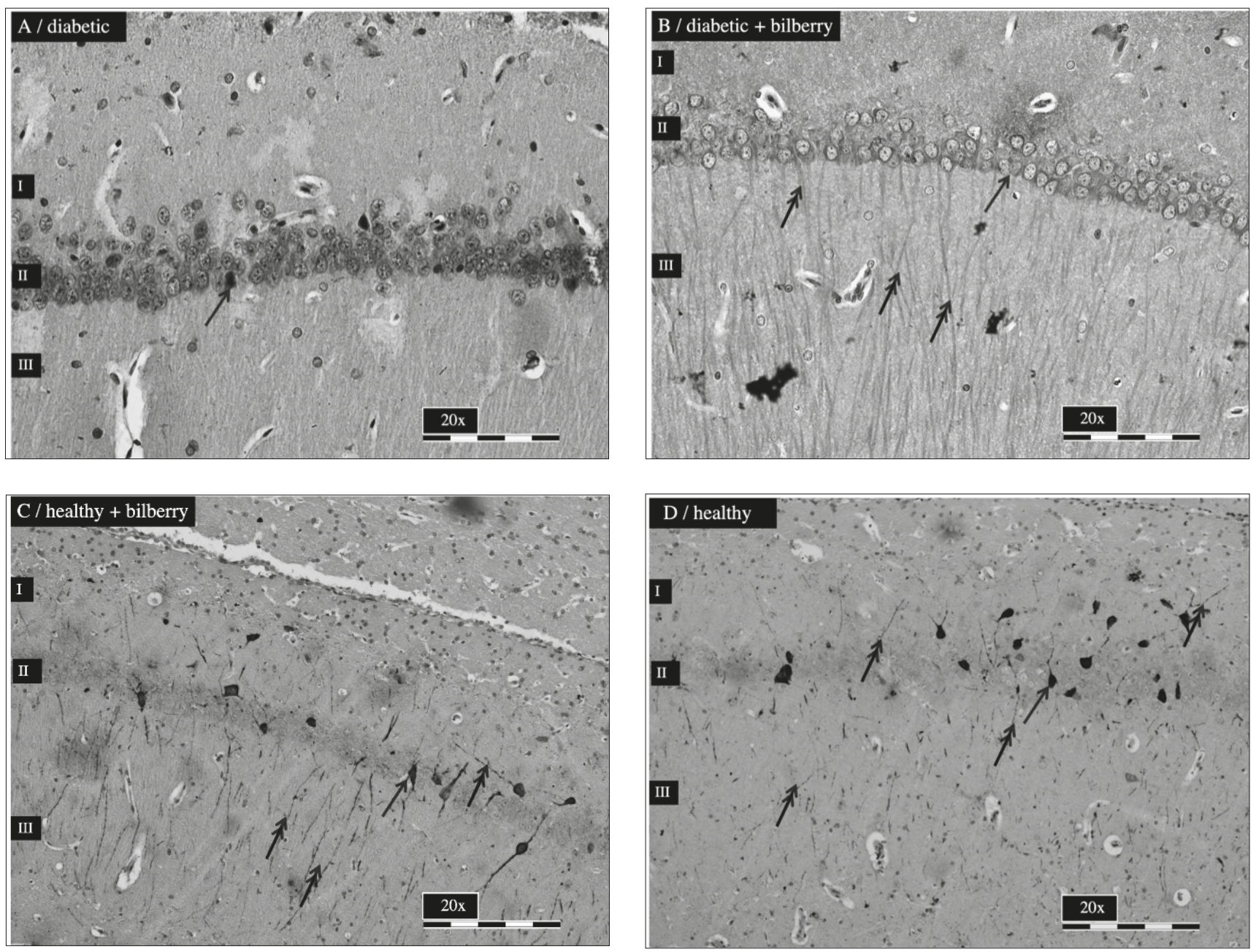

Figure 3. Immunoreactivity of InRs in moderate numbers of neurons of the rat field CA1 of the hippocampus is observed.

(A) diabetic group, $n=8$; (B) diabetic group fed with bilberry pulp, $n=8$; (C) healthy group fed with bilberry pulp, $n=10 ;(D)$ healthy group, $n=10$. I. the marginal layer II. the pyramidal layer III. the multiform layer. The arrows indicate InRs-ir neurons (single arrow) and InRs-ir fibres (double arrow) in the CA1 field of the hippocampus. Magnification $\times 20(A-D)$ 
bilberry extracts were also confirmed using different methods and summarised by Hidalgo and Almajano [30].

Taking the composition of bilberry fruit into account (phenolic compounds as well as simple sugars) [31], the control of selected biochemical parameters of blood was found to be highly justified. However, not only the presented results but also the results of previous studies are quite inconclusive. On the one hand, no differences in lipid metabolism, glucose levels or body weight were revealed in the study of people (aged ca. 50 years, $n=15$ ) who consumed an equivalent dose of $400 \mathrm{~g}$ of fresh bilberries for 8 weeks, compared to a control group (aged ca. 50 years, $n=15$ ) [32]. Another example is the experiment on STZ-induced diabetic rats exhibiting hyperglycaemia after 6 weeks, in which oral administration of bilberry extract ( $\left.100 \mathrm{mg} \mathrm{kg}^{-1}\right)$ did not affect blood glucose levels and body weight [33]. There were also no differences in the levels of total cholesterol or HDL- or LDL-cholesterol between diabetic rats fed with bilberry $(6.25 \%$, w/w in feed for 4 weeks) and a control group receiving standard feed, as reported by other researchers [34].

But on the other hand, there are studies which proved certain effects of bilberry on biochemical parameters in vivo, e.g. the reduced concentration of glucose as well as total cholesterol, LDL-cholesterol and triglycerides in alloxaninduced diabetic rats [35], decreased concentrations of total cholesterol, but unchanged levels of glucose and triglycerides [36]. Increased HDL-cholesterol and decreased levels of LDLcholesterol and triglycerides were observed in the plasma of volunteers who consumed $150 \mathrm{~g}$ of frozen stored bilberries 3 times a week for 6 weeks [37]. Moreover, the anti-diabetic effects of bilberry are quite well documented [38]. The decrease in blood glucose and serum insulin and glucose levels were reported after incorporating bilberry extract in the diet of rats suffering from diabetes type 1 for a period of 8 weeks [4]. It has also been proven that postprandial insulin response decreased in persons whose diets were enriched with bilberry [5].

Although the peripheral effects of bilberry in living organisms are ambiguous, its role in the treatment of DM is still important and needs to be explored. In addition, DM also resulted in the disruption of glucose homeostasis in the CNS [39]. Several reports have shown that cognitive functions are disturbed in the course of diabetes, which is associated with structural and electrophysiological alterations and brain atrophy $[14,40]$. These changes refer to several structures in the temporal lobe, especially the hippocampus, considered the cerebral centre of memory and reasoning. Moreover, a previous study reported that the density of dendritic spines decreased in pyramidal cells from diabetic animals, especially in the CA1 field of hippocampus [41]. Likewise, dendritic atrophy in hippocampal neurons (CA3 field) of rats with experimentally induced diabetes was noted [42]. In addition, a reduced number of neurons in the hippocampal CA1 field was reported after long-term diabetes [43]. According to the previous study [44], the hippocampus responds to chronic diabetes by atrophy (shrinking), but is also capable of significant structural reorganization, including dendritic remodelling. And finally, the animal models of metabolic alterations demonstrate reduction in neuronal density and overall brain atrophy [45].

InRs, located on nerve cell, are unevenly distributed in the CNS, but are especially numerous in areas responsiblse for cognitive processes (hippocampus, frontal cortex, hypothalamus) [46]. Therefore, a relationship between insulin and memory or cognition can be considered [15]. Based on previous findings [16], it can be argued that during the course of neurodegenerative diseases, such as AD or Parkinson's disease, the level of expression of InRs in the brain's structures decreases. At the most advanced stage of $\mathrm{AD}$, InRs were nearly $80 \%$ less numerous compared to a healthy brain [12].

It is worth emphasising the increase in the number of InRs-ir in the diabetic group with bilberry supplementation, in comparison to the control diabetic group. At present, there is little information in the literature on the impact of bilberries on the CNS in the course of diabetes. The previous, pioneer study by the authors of the current study showed that antioxidants present in bilberry fruit affect morphology, and probably show beneficial effects on hippocampal neurons during diabetes [39]. It was also shown that long-term supplementation with bilberry extract prevents learning deficits, as discussed by Subash et al. [47]. As previously mentioned, bilberry is a well-known source of flavonoids and one of their effects is preventing diabetes.

\section{CONCLUSIONS}

Bilberry is a valuable source of polyphenolic compounds and a source of antioxidant activity. The results of analysis of the blood/plasma biochemical parameters are ambiguous, and no significant effects $(\mathrm{P}<0.05)$ of bilberry supplementation on their levels in diabetic rats have been confirmed. However, a significant increase in the number of InRs-ir in the diabetic group with bilberry supplementation, compared with the control diabetic group, was affirmed. Interestingly, a positive effect of bilberry supplementation in diabetic animals was observed only in the cytoplasm, while in the control normal group, a positive response was observed both in the cell nucleus and in the cytoplasm. A positive reaction was also observed in the dendritic fibres.

\section{REFERENCES}

1. Dragan S, Andrica F, Serban M-C, et al. Polyphenols-rich natural products for treatment of diabetes. Curr Med Chem. 2015; 22(1): 14-22. doi: 10.2174/0929867321666140826115422

2. Sidorova Y, Shipelin V, Mazo V, et al. Hypoglycemic and hypolipidemic effect of Vaccinium myrtillus L. leaf and Phaseolus vulgaris L. seed coat extracts in diabetic rats. Nutrition. 2017; 41: 107-112. doi: 10.1016/j. nut.2017.04.010

3. Hoggard N, Cruickshank M, Moar K, et al. A single supplement of a standardised bilberry (Vaccinium myrtillus L.) extract (36\% wet weight anthocyanins) modifies glycaemic response in individuals with type 2 diabetes controlled by diet and lifestyle. J Nutr Sci. 2013; 2: e22. doi: 10.1017/jns.2013.16. eCollection 2013

4. Ştefănescu (Braic) R, Vari C, Imre S, et al. Vaccinium extracts as modulators in experimental type 1 diabetes. J Med Food. 2018; 21(11): 1106-1112. doi: 10.1089/jmf.2017.0141

5. Törrönen R, Kolehmainen M, Sarkkinen E, et al. Berries reduce postprandial insulin responses to wheat and rye breads in healthy women. J Nutr. 2013; 143(4): 430-436. doi: 10.3945/jn.112.169771

6. Ancillotti C, Ciofi L, Rossini D, et al. Liquid chromatographic/ electrospray ionization quadrupole/time of flight tandem mass spectrometric study of polyphenolic composition of different Vaccinium berry species and their comparative evaluation. Anal Bioanal Chem. 2017; 409(5): 1347-1368. doi: 10.1007/s00216-016-0067-y

7. Ştefanuț MN, Cata A, Pop R, et al. Anti-hyperglycemic effect of bilberry, blackberry and mulberry ultrasonic extracts on diabetic rats. Plant Foods Hum Nutr. 2013; 68(4): 378-384. doi: 10.1007/s11130-013-0380-y 
8. Varut RM, Gîrd CE, Rotaru LT, et al. Evaluation of polyphenol and flavonoid profiles and the antioxidant effect of Carduus acanthoides hydroalcoholic extract compared with Vaccinium myrtillus in an animal model of diabetes mellitus. Pharm Chem J. 2018; 51(879): 1088-1095. doi: 10.1007/s11094-018-1746-0

9. Borowiec K, Szwajgier D, Targoński Z, et al. Cholinesterase inhibitors isolated from bilberry fruit. J Funct Foods. 2014; 11: 313-321. doi: 10.1016/j.jff.2014.10.008

10. Szwajgier D, Borowiec K. Screening for cholinesterase inhibitors in selected fruits and vegetables. Electron J Pol Agric Univ. 2012; 15(2): 6.

11. Nguyen TT, Ta QTH, Nguyen TKO, et al. Type 3 diabetes and its role implications in Alzheimer's disease. Int J Mol Sci. 2020; 21(9): 3165. doi: 10.3390/ijms21093165

12. Ferreira LSS, Fernandes CS, Vieira MNN, et al. Insulin resistance in Alzheimer's Disease. Front Neurosci. 2018; 12: 830. doi: 10.3389/ fnins.2018.00830

13. Moheet A, Mangia S, Seaquist ER. Impact of diabetes on cognitive function and brain structure. Ann NY Acad Sci. 2015; 1353: 60-71. doi: $10.1111 /$ nyas. 12807

14. Ho N, Sommers MS, Lucki I. Effects of diabetes on hippocampal neurogenesis: links to cognition and depression. Neurosci Biobehav Rev. 2013; 37(8): 1346-1362. doi: 10.1016/j.neubiorev.2013.03.010

15. Pomytkin I, Costa-Nunes JP, Kasatkin V, et al. Insulin receptor in the brain: Mechanisms of activation and the role in the CNS pathology and treatment. CNS Neurosci Ther. 2018; 24(9): 763-774. doi: 10.1111/ cns. 12866

16. Soto M, Cai W, Konishi M, et al. Insulin signaling in the hippocampus and amygdala regulates metabolism and neurobehavior. Proc Natl Acad Sci U S A. 2019; 116(13): 6379-6384. doi: 10.1073/pnas.1817391116

17. Banks WA, Owen JB, Erickson MA. Insulin in the brain: there and back again. Pharmacol Ther. 2012; 136(1): 82-93. doi: 10.1016/j. pharmthera.2012.07.006

18. De Felice FG, Benedict C. A key role of insulin receptors in memory. Diabetes. 2015; 64(11): 3653-3655. doi: 10.2337/dbi15-0011

19. Bobinaitė R, Viškelis P, Venskutonis PR. Variation of total phenolics, anthocyanins, ellagic acid and radical scavenging capacity in various raspberry (Rubus spp.) cultivars. Food Chem. 2012; 132(3): 1495-1501. doi: 10.1016/j.foodchem.2011.11.137

20. Brand-Williams W, Cuvelier ME, Berset C. Use of free radical method to evaluate antioxidant activity. Lebensm-Wiss Technol. 1995; 28(1): 2525-2530. doi: 10.1016/S0023-6438(95)80008-5

21. Miller NJ, Rice-Evans C, Davies MJ, et al. A novel method for measuring antioxidant capacity and its application to monitoring the antioxidant status in premature neonates. Clin Sci (Lond). 1993; 84(4): 407-412. doi: $10.1042 / \operatorname{cs} 0840407$

22. Chandirasegaran G, Elanchezhiyan C, Ghosh K, et al. Berberine chloride ameliorates oxidative stress, inflammation and apoptosis in the pancreas of streptozotocin induced diabetic rats. Biomed Pharmacother. 2017; 95: 175-185. doi: 10.1016/j.biopha.2017.08.040

23. Masuda K, Aizawa N, Watanabe D, et al. Pathophysiological changes of the lower urinary tract behind voiding dysfunction in streptozotocininduced long-term diabetic rats. Sci Rep. 2020; 10: 4182. doi: 10.1038/ s41598-020-61106-y

24. Nair AB, Jacob S. A simple practice guide for dose conversion between animals and human. J Basic Clin Pharm. 2016; 7(2): 27-31. doi: 10.4103/0976-0105.177703

25. Matysek M, Krakowska I, Lonc G, et al. Expression of $\alpha$ and $\beta$ oestrogen receptors within the claustrum in rabbit males. Bull Vet Inst Pulawy. 2014; 58(1): 157-161. doi: 10.2478/bvip-2014-0024

26. Kunachowicz H, Przygoda B, Nadolna I, et al. Tabele składu i wartości odżywczej żywności. 4th ed. Wydawnictwo Lekarskie PZWL, 2017.

27. Zhou Q, Wu J, Tang J, et al. Beneficial effect of higher dietary fiber intake on plasma HDL-C and TC/HDL-C ratio among Chinese ruralto-urban migrant workers. Int J Environ Res Public Health. 2015; 12(5): 4726-4738. doi: 10.3390/ijerph120504726

28. Aaby K, Grimmer S, Holtung L. Extraction of phenolic compounds from bilberry (Vaccinium myrtillus L.) press residue: Effects on phenolic composition and cell proliferation. LWT-Food Sci Technol. 2013; 54(1): 257-264. doi: 10.1016/j.lwt.2013.05.031
29. Tian Y, Liimatainen J, Alanne AL, et al. Phenolic compounds extracted by acidic aqueous ethanol from berries and leaves of different berry plants. Food Chem. 2017; 220: 266-281. doi: 10.1016/j.foodchem.2016.09.145

30. Hidalgo G-I, Almajano MP. Red fruits: Extraction of antioxidants, phenolic content, and radical scavenging determination: A review. Antioxidants (Basel). 2017; 6(1): 7. doi: 10.3390/antiox6010007

31. Mikulic-Petkovsek M, Schmitzer V, Slatnar A, et al. A comparison of fruit quality parameters of wild bilberry (Vaccinium myrtillus L.) growing at different locations. J Sci Food Agric. 2015; 95(4): 776-785. doi: $10.1002 /$ jsfa. 6897

32. Kolehmainen M, Mykkänen O, Kirjavainen PV, et al. Bilberries reduce low-grade inflammation in individuals with features of metabolic syndrome. Mol Nutr Food Res. 2012; 56(10): 1501-1510. doi: 10.1002/ mnfr.201200195

33. Kim J, Kim CS, Lee YM, et al. Vaccinium myrtillus extract prevents or delays the onset of diabetes-induced blood-retinal barrier breakdown. Int J Food Sci Nutr. 2015; 66(2): 236-242. doi: 10.3109/09637486.2014.979319

34. Roghani M, Baluchnejadmojarad T, Taheri S. The effect of feeding with aerial part of Vaccinium myrtillus on blood glucose and lipids of diabetic rats. Iran J Diabetes Lipid Disord. 2007; 7: 151-158.

35. Asgary S, RafieianKopaei M, Sahebkar A, et al. Anti-hyperglycemic and anti-hyperlipidemic effects of Vaccinium myrtillus fruit in experimentally induced diabetes (antidiabetic effect of Vaccinium myrtillus fruit). J Sci Food Agric. 2016; 96(3): 764-768. doi: 10.1002/ jsfa.7144

36. Madihi Y, Merrikhi A, Baradaran A, et al. Bioactive components and the effect of hydroalcoholic extract of Vaccinium myrtillus on postprandial atherosclerosis risk factors in rabbits. Pak J Med Sci. 2013; 29(1): 384-389. doi: 10.12669/pjms.291(Suppl).3539

37. Habanova M., Saraiva JA, Haban M, et al. Intake of bilberries (Vaccinium myrtillus L.) reduced risk factors for cardiovascular disease by inducing favorable changes in lipoprotein profiles. Nutr Res. 2016; 36(12): 1415-1422. doi: 10.1016/j.nutres.2016.11.010

38. Crespo MC, Visioli F. A brief review of blue- and bilberries' potential to curb cardio-metabolic perturbations: Focus on diabetes. Curr Pharm Des. 2017; 23(7): 983-988. doi: 10.2174/1381612822666161010120523

39. Matysek M, Mozel S, Szalak R, et al. Effect of feeding with bilberry fruit on the expression pattern of aCaMKII in hippocampal neurons in normal and diabetic rats. Pol J Vet Sci. 2017; 20(2): 313-319. doi: 10.1515/pjvs-2017-0038

40. Vogt MC, Brüning JC. CNS insulin signaling in the control of energy homeostasis and glucose metabolism-from embryo to old age. Trends Endocrinol Metab. 2013; 24(2): 76-84. doi: 10.1016/j.tem.2012.11.004

41. Jayaraj RL, Azimullah S, Beiram R. Diabetes as a risk factor for Alzheimer's disease in the Middle East and its shared pathological mediators. Saudi J Biol Sci. 2020; 27(2): 736-750. doi: 10.1016/j. sjbs.2019.12.028

42. Stranahan AM. Models and mechanisms for hippocampal dysfunction in obesity and diabetes. Neuroscience. 2015; 19(309): 125-139. doi: 10.1016/j.neuroscience.2015.04.045

43. Derakhshan F, Toth C. Insulin and the brain. Curr Diabetes Rev. 2013; 9(2): 102-116.

44. Zhang G, Fang H, Li Y, et al. Neuroprotective effect of astragalus polysacharin on streptozotocin (STZ)-induced diabetic rats. Med Sci Monit. 2019; 25: 135-141. doi: 10.12659/MSM.912213

45. Infante-Garcia C, Ramos-Rodriguez JJ, Galindo-Gonzalez L, et al. Long-term central pathology and cognitive impairment are exacerbated in a mixed model of Alzheimer's disease and type 2 diabetes. Psychoneuroendocrinology. 2016; 65: 15-25. doi: 10.1016/j. psyneuen.2015.12.001

46. Grillo CA, Woodruff JL, Macht VA et al. Insulin resistance and hippocampal dysfunction: Disentangling peripheral and brain causes from consequences. Exp Neurol. 2019; 318: 71-77. doi: 10.1016/j. expneurol.2019.04.012

47. Subash S, Essa MM, Al-Adawi S, et al. Neuroprotective effects of berry fruits on neurodegenerative diseases. Neural Regen Res. 2014; 9(16): 1557-66. doi: 10.4103/1673-5374.139483 